\title{
Characterization of Fatigue Crack Growth Behavior in LENS Fabricated Ti-6Al-4V Using High- Energy Synchrotron X-ray Microtomography
}

\author{
Hayley R. Sandgren ${ }^{\mathrm{a}}$, Yuwei Zhai ${ }^{\mathrm{a}, *}$, Diana A. Lados ${ }^{\mathrm{a}}$, Paul A. Shade ${ }^{\mathrm{b}}$, Jay C. Schuren ${ }^{\mathrm{c}}$, Michael A. \\ Groeber $^{\mathrm{b}}$, Peter Kenesei ${ }^{\mathrm{d}}$, Anastasios G. Gavras ${ }^{\mathrm{e}}$
}

${ }^{a}$ Worcester Polytechnic Institute, Integrative Materials Design Center, Worcester, MA 01609, USA

b Materials and Manufacturing Directorate, Air Force Research Laboratory, Wright-Patterson AFB, OH 45433, USA

${ }^{\mathrm{c}}$ Nutonian, Inc., Somerville, MA 02144, USA

${ }^{\mathrm{d}}$ Advanced Photon Source, Argonne National Laboratory, Argonne, IL 60439, USA

${ }^{\mathrm{e}}$ Babcock Power, Worcester, MA 01609, USA

*Corresponding author's email address: yzhai@ wpi.edu

Postal address: 100 Institute Road, Washburn shop, Room 249, Worcester, MA 01609

\begin{abstract}
Laser Engineered Net Shaping (LENS) is an additive manufacturing technique that belongs to the ASTM standardized directed energy deposition category. To date, very limited work has been conducted towards understanding the fatigue crack growth behavior of LENS fabricated materials, which hinders the widespread adoption of this technology for high-integrity structural applications. In this study, the propagation of a $20 \mu \mathrm{m}$ initial crack in LENS fabricated Ti-6Al-4V was captured in-situ, using highenergy synchrotron x-ray microtomography. Fatigue crack growth (FCG) data were then determined from 2D and 3D tomography reconstructions, as well as from fracture surface striation measurements using SEM. The generated data were compared to those obtained from conventional FCG tests that used compliance and direct current potential drop (DCPD) techniques to measure long and small crack growth. The observed agreement demonstrates that x-ray microtomography and fractographic analysis using SEM can be successfully combined to study the propagation behavior of fatigue cracks.
\end{abstract}

Keywords: LENS fabricated Ti-6Al-4V, High-energy synchrotron x-ray microtomography, 3D characterization of fatigue crack growth

\section{Introduction}

Laser Engineered Net Shaping (LENS) is an Additive Manufacturing (AM) technique developed at Sandia National Laboratories, specifically for the free form fabrication of metallic materials. During the LENS process, metal powder is fused by a laser beam, and selectively deposited onto a substrate. This working principle classifies LENS in the directed energy deposition category according to ISO/ASTM 52900 [1]. Applications of LENS include rapid prototyping, short run production, and manufacturing and repair of structural components, using various materials such as stainless steel, titanium and nickel alloys, as well as functionally graded materials. Comparing to AM techniques that belong to the powder bed fusion category, LENS is also able to process larger objects. These advantages make LENS attractive to critical industries including aerospace, defense, and medical.

Ti-6Al-4V alloy is widely used in critical applications due to its high specific strength and corrosion resistance, and can be successfully manufactured by LENS. Numerous studies have investigated the microstructure and tensile properties of LENS fabricated Ti-6Al-4V [2-10]. It was observed that the cyclic heating and fast cooling during this process result in unique microstructural features, including large columnar $\beta$ grains, remelt/reheat zones between layers, fine $\alpha+\beta$ basketweave morphology, and in some cases martensitic $\alpha$ ' phase. The tensile strength was found comparable to that of the conventionally manufactured Ti-6Al-4V, but with lower ductility. In terms of the material's fatigue resistance, Sterling et 
al. [7] observed shorter high cycle fatigue lives in LENS fabricated Ti-6Al-4V compare to the wrought materials, which were attributed to porosity and the lack of ductility. Amsterdam and Kool [8] however, found similar high cycle fatigue performance in LENS and wrought Ti-6Al-4V, despite the presence of severe porosity. This fatigue data inconsistence was also reported by Bian et al. [9], attributed to the differences in processing parameters that led to different microstructures and porosity levels.

In the presence of pre-existing flaws, a representative situation for additively manufactured materials, damage tolerant design and fatigue crack growth (FCG) data are required. To date, very limited FCG data are available in the literature for LENS fabricated Ti-6Al-4V [10]. Compared to wrought materials, Zhai et al. reported lower FCG threshold values and faster crack propagation rates in Regions I and II of FCG. Slower FCG rates in Region III was found to yield higher fracture toughness values. Small fatigue crack propagation behavior was also investigated, using direct current potential drop (DCPD) technique and an initial flaw size of $100 \mu \mathrm{m}$. The typical acceleration/retardation behavior of the small cracks was captured in this study. However, the likelihood of crack initiation from the competing spot welds or pores instead of the initial flaw yields low success rate during experimentation, making DCPD technique inconvenient to use.

$\mathrm{X}$-ray microtomography has recently proven to be a valuable tool for both in-situ and post-mortem studies of fatigue behavior [11-24]. Rethore et al. [11] used a shape detection algorithm to capture the crack geometry in heat treated cast iron. Stress intensity factors and crack tip positions were also found for all tomographic scans. Singh et al. [12] performed an in-situ study of corrosion fatigue in an aluminum alloy. Corrosion products, corrosive fluid, and the fatigue crack were observed using tomography 3D imaging. This study confirmed tomography's great potential for use in studying fatigue behavior as it enabled high-resolution observation of fatigue crack evolution over time. Williams et al. $[13,14]$ conducted another set of experiments that utilized tomography to analyze FCG in aluminum alloys. In these studies, 3D tomography data were used to obtain local crack growth rates $(\mathrm{da} / \mathrm{dN})$, which varied significantly throughout the sample, demonstrating that local growth rates were a more accurate representation of the small crack growth behavior [13]. In addition, they evaluated the accuracy of tomographic measurements. Their findings verified tomography as an accurate and useful tool for calculating local crack growth rates [14]. Birosca et al. [17,18] utilized x-ray tomography to study the fatigue crack propagation in-situ in powder-processed $\alpha+\beta$ titanium alloys, heat treated to various $\alpha$ morphologies. Chronological description of the crack, and identification of the prior $\beta$ boundaries were achieved. Combining with the application of EBSD, the role of $\beta$ grain boundaries, importance of $\alpha$ morphologies, and crystal orientations were demonstrated. King et al. [20] studied the growth behavior of short fatigue cracks in a cast magnesium alloy, using a combination of $x$-ray diffraction contrast tomography (DCT) and microtomography. Qualitative explanation for the observed 3D behavior of a short fatigue crack can be achieved applying grain shapes and crystallographic orientations.

In this study, high-energy absorption contrast synchrotron microtomography was employed to investigate the growth of a $20 \mu \mathrm{m}$ initial crack in-situ, in order to explore and define alternative solutions for capturing the growth behavior of small fatigue cracks in LENS fabricated Ti-6Al-4V. Stress intensity factors $(\Delta \mathrm{K}$ values) and corresponding crack propagation rates $(\mathrm{da} / \mathrm{dN})$ were determined from $2 \mathrm{D}$ and $3 \mathrm{D}$ microtomography reconstructions, as well as from fatigue striation measurements. These data were compared to those obtained from conventional FCG tests using compliance and DCPD techniques for crack growth measurements. Results generated in this study demonstrates the potential of applying x-ray microtomography in fatigue crack growth testing, while emphasizing the importance of 3D understanding of FCG for further design and materials/process optimization.

\section{Material and methods}

\subsection{Material and microstructure}

In this study, Ti-6Al-4V samples were fabricated by an Optomec LENS 850R system, using the processing parameters shown in Table 1. The feedstock material was gas atomized (GA) Ti-6Al-4V 
spherical powder $(-100+325$ mesh size) provided by Crucible Research. A cross-hatched deposition protocol was used with a $90^{\circ}$ hatching angle between alternating layers, which was found to provide materials with a lower porosity level.

\section{Table 1}

LENS processing parameters

$\begin{array}{cc}\text { Laser Power } & 330[\mathrm{~W}] \\ \text { Beam Diameter } & 0.6[\mathrm{~mm}] \\ \text { Powder Feed Rate } & 1.0[\mathrm{~g} / \mathrm{min}] \\ \text { Layer Thickness } & 0.3[\mathrm{~mm}] \\ \text { Hatch Spacing } & 0.5[\mathrm{~mm}] \\ \text { Deposition Speed } & 550[\mathrm{~mm} / \mathrm{min}]\end{array}$

The resultant microstructure consists of large columnar $\beta$ grains (1-20 mm long and 0.2-4.0 mm wide) perpendicular to the substrate, i.e., the cooling gradient direction, as shown in Figure 1(a), where D stands for deposition direction. Layer bands were also observed, Figures 1(b,c), where the layer thickness varied between $300 \mu \mathrm{m}$ and $800 \mu \mathrm{m}$ (measured by Element-D image analysis software). Very fine $\alpha$ ' phase (5-20 $\mu \mathrm{m}$ long and $\sim 0.7 \mu \mathrm{m}$ thick) was observed within the columnar grains due to fast cooling, as shown in Figure 1(d). A coarser microstructure was observed in between layers (micro-HAZ), as shown in Figure 1(e), due to re-melting/re-heating of previous layers upon subsequent depositions.

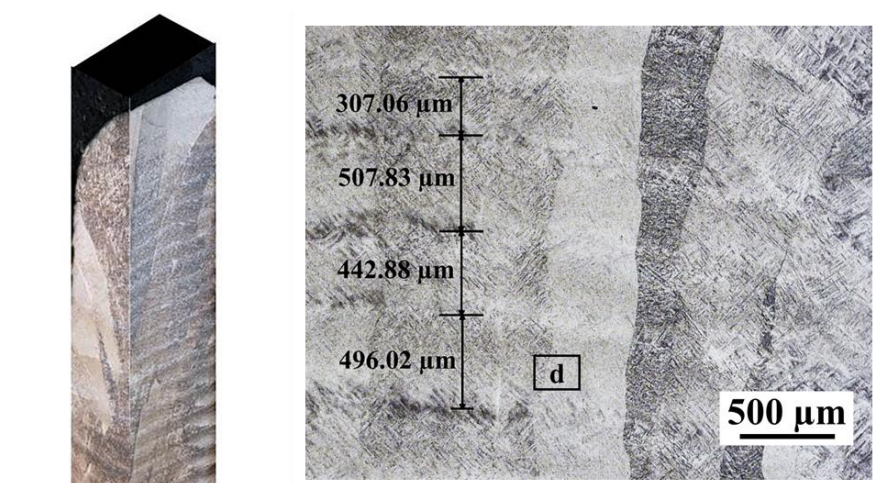

(b)

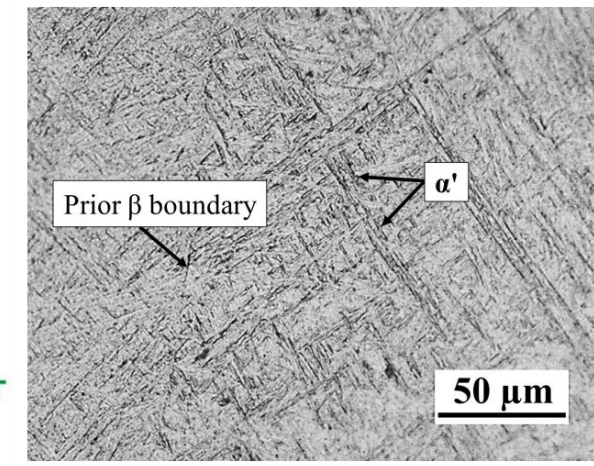

(d)

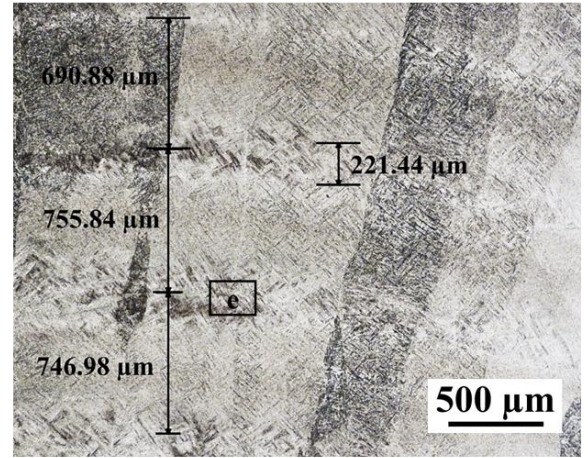

(c)

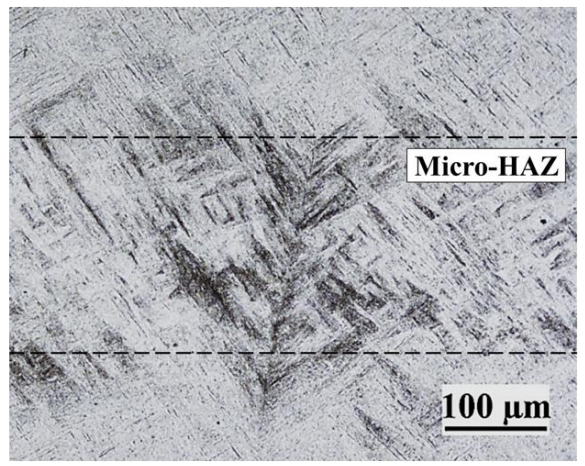

(e)

Fig. 1. Microstructure analysis of LENS fabricated Ti-6Al-4V: (a) panoramic view (constructed from the cross-sections of a $40 \mathrm{~mm}$ tall deposition) showing columnar grains and layer bands; (b,c) various layer thicknesses (thinner at bottom and thicker towards top of the build); (d) fine martensitic microstructure;

(e) coarser microstructure within micro-HAZ due to reheating/remelting of previous layers. 


\subsection{Fatigue crack growth behavior in LENS Ti-6Al-4V captured using conventional methodologies}

Previous studies conducted by Zhai et al. [10] investigated the propagation behavior of both long and small fatigue cracks in LENS Ti-6Al-4V manufactured by the same set of parameters. Based on ASTM E647 [25], long FCG tests were performed on compact tension specimens, using compliance technique to monitor crack propagation. Surface flaw tension specimens were utilized for small FCG testing, and DCPD technique was employed to measure crack growth. Both long and small FCG data obtained are plotted together with those of conventional mill-annealed Ti-6Al-4V in Figure 2(a). Lower threshold and higher fracture toughness values were observed in LENS material, attributed to the crack interaction with fine $\alpha$ ' martensitic phase in all stages of crack growth, Figures 2(b-d). The small FCG data appeared a typical acceleration and retardation in crack growth rates, due to local interactions between the small crack and the material's characteristic microstructural features. For LENS Ti-6Al-4V, these were identified to be prior $\beta$ columnar grain boundaries, which acted as barriers for crack growth, as shown in Figures 2(e,f).

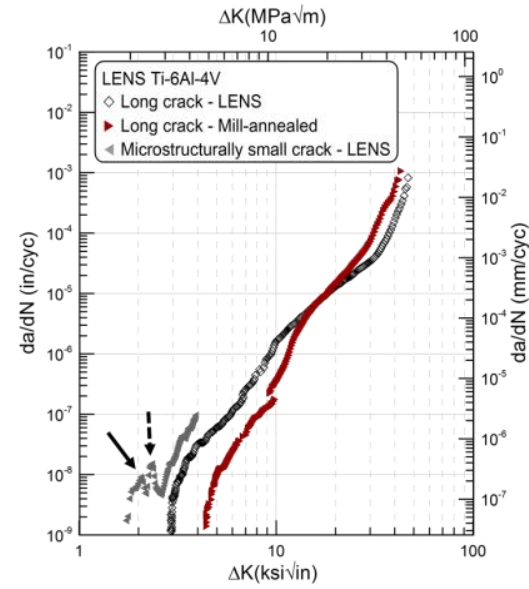

(a)

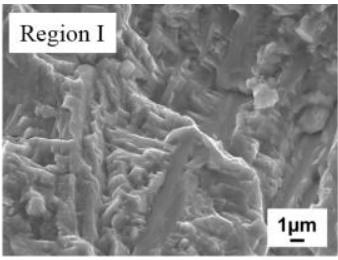

(b) $\Delta \mathrm{K} \sim 2.7 \mathrm{MPa} \sqrt{\mathrm{m}}$

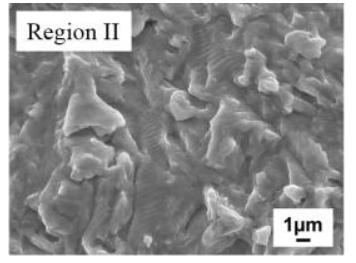

(c) $\Delta \mathrm{K} \sim 13 \mathrm{MPa} \sqrt{\mathrm{m}}$

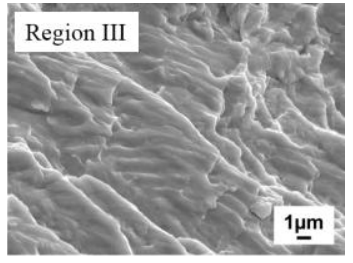

(d) $\Delta \mathrm{K} \sim 30 \mathrm{MPa} \sqrt{\mathrm{m}}$

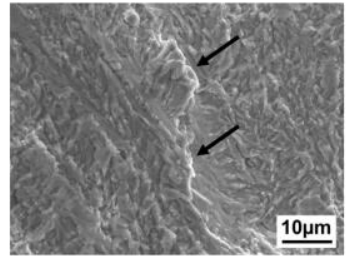

(e) $\Delta \mathrm{K} \sim 2.1 \mathrm{MPa} \sqrt{\mathrm{m}}$

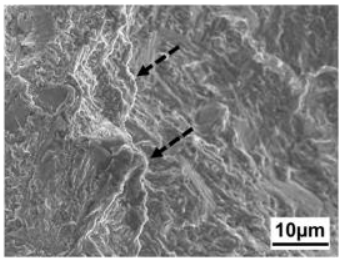

(f) $\Delta \mathrm{K} \sim 2.3 \mathrm{MPa} \sqrt{\mathrm{m}}$

Fig. 2. (a) Long and small FCG data in LENS fabricated Ti-6Al-4V tested at $\mathrm{R}=0.1$, compared to millannealed Ti-6Al-4V; (b-d) fractographs from long FCG threshold, Region II, and Region III; and (e,f) fractographs showing evidences of small crack's interaction with $\beta$ grain boundaries at the growth rate retardation points, as indicated by the arrows [10].

\subsection{Preparation and testing of the microtomography specimen}

Testing specimens for in-situ microtomography experiments were machined using wire EDM according to the geometry shown in Figure 3, with a total length of $26 \mathrm{~mm}$, gage length of $8 \mathrm{~mm}$, and a square $1 \mathrm{~mm} \times 1 \mathrm{~mm}$ gage cross-section. Three specimens were machined out of a LENS fabricated Ti6Al-4V block at various locations, Figure 4(a), followed by electropolishing to remove any residual surface damage. Then a $20 \mu \mathrm{m}$ long corner flaw was introduced into the specimens carefully through focused ion beam (FIB) machining using an FEI DB235 FIB-SEM. Specimen 1 in Figure 4(a) was tested at Argonne National Laboratory (ANL) under the assigned beam time. The location of the corner crack with respect to the microstructure of the material is schematically illustrated in Figure 4(b). The other two specimens will be included in the future work. 

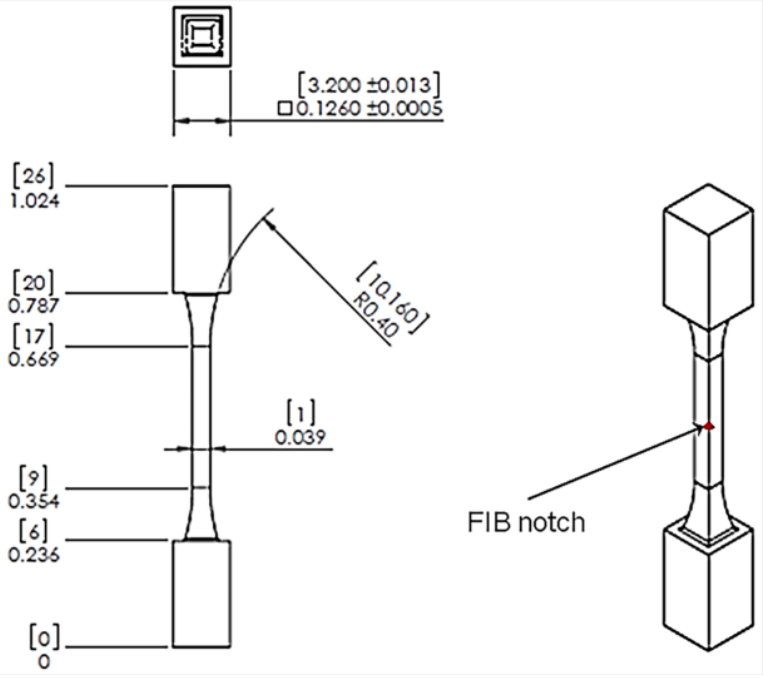

Fig. 3. Tomography specimen geometry (SI units in brackets); initial FIB corner notch is $20 \mu \mathrm{m}$ in radius.

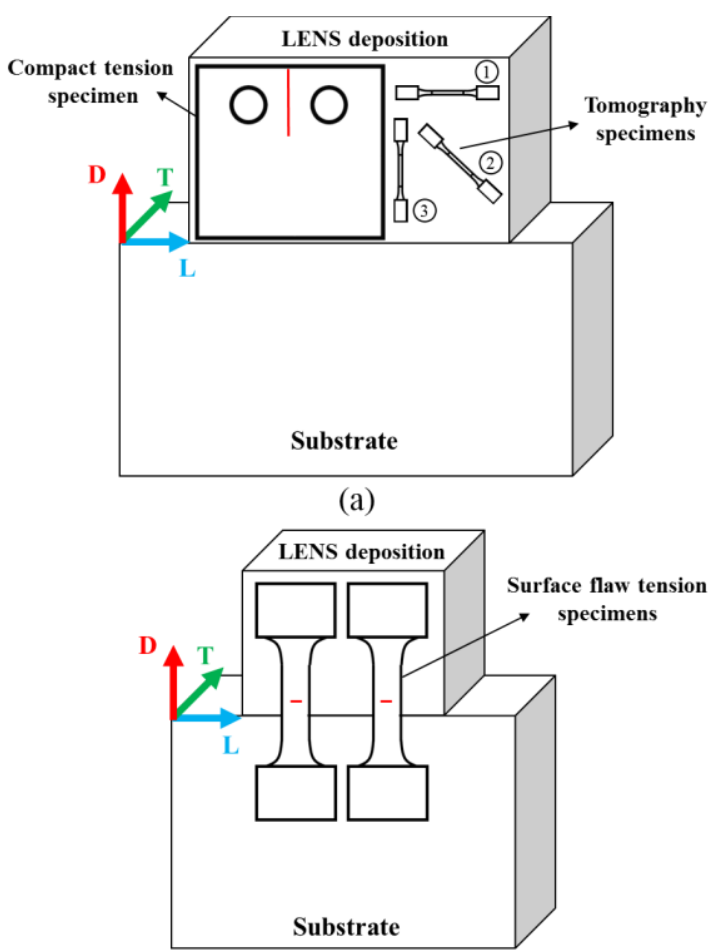

(b)

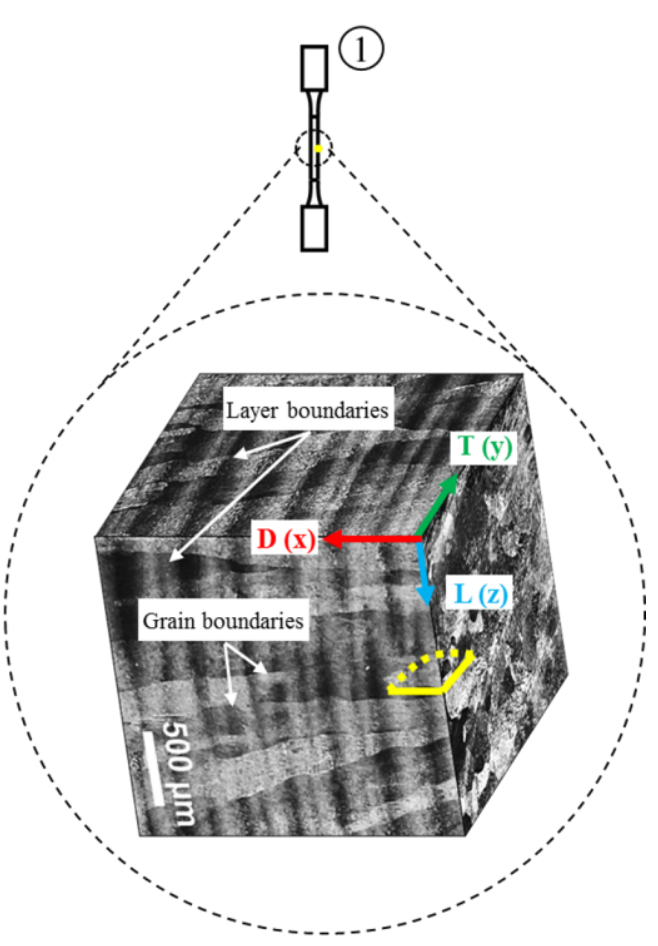

(c)

Fig. 4. $(a, b)$ Schematic illustration showing the location of the compact tension, tomography and surface flaw tension specimens within the LENS depositions; (c) illustration of the corner crack with respect to the oriented microstructure (note that the size of the corner crack in the illustration is not proportional to the scale bar).

In-situ interrupted cyclic loading and microtomography measurements were conducted using the high-energy synchrotron beamline 1-ID-E at the Advanced Photon Source (APS), ANL. Sample loading was accomplished using a rotation and axial motion system inserted into the grips of an MTS model 858 load frame that enabled the specimen to be rotated through a continuous $360^{\circ}$ range while simultaneously and independently applying axial loads [26,27]. The specimen was subjected to cyclic loads at a low stress ratio, $R=0.1$, and low cyclic frequency, $f=2.5 \mathrm{~Hz}$, in room temperature air. Cyclic frequency was 
kept constant throughout the test. All FCG experiments were conducted in load control, and after a given number of cycles the sample was returned to and held at the peak load to ensure maximum crack tip opening (i.e., visibility) during microtomography measurements. These measurements were collected with a monochromatic synchrotron x-ray beam at an energy of $52 \mathrm{keV}$. The $2 \mathrm{D}$ projections of the sample (radiographs) were captured through a range of $360^{\circ}$ in $0.2^{\circ}$ rotation intervals. Absorption contrast enabled the structure of the crack to be determined during each load hold.

The applied stress $(\sigma)$ was determined using the simple derivative of fracture mechanics, equation (i) [28], based on the $20 \mu \mathrm{m}$ initial flaw size (a) and the desired stress intensity factor value $(\Delta \mathrm{K})$ of 2.0 $\mathrm{MPa} \sqrt{ }$, corresponding to the crack growth threshold value obtained from previous small FCG test, Figure 2(a). A Y value of 1.03 was used in the calculation for the corner flaw geometry.

$$
\Delta K=\frac{2}{\pi} Y \Delta \sigma \sqrt{\pi \mathrm{a}}
$$

The calculated cyclic loading parameters were $43.9 \mathrm{~N}$ minimum and $439 \mathrm{~N}$ maximum. However, after a total of 76,050 cycles, no crack growth was observed. The load was therefore increased to 87.8/878 $\mathrm{N}$ $(\mathrm{min} / \mathrm{max})$, where minimal crack growth was observed after 4,200 cycles. After a total of 12,000 cycles at $87.8 / 878 \mathrm{~N}(\mathrm{~min} / \mathrm{max}$ ), the load was again increased to $100 / 1000 \mathrm{~N}$ (with $\Delta \sigma=900 M P a, \Delta K=4.68$ $M P a \sqrt{ }$ ) to induce faster crack growth. A total of seven tomography scans were taken between the start of crack growth and specimen failure. Scans 1-3 were taken with the 87.8/878 N load interval, and scans 4-7 were taken with the 100/1000 N load interval. After each cycle interval, as described in Table 2, the fatigue test was interrupted and the sample was held under tension at the maximum load for approximately $30 \mathrm{~min}$ while the microtomography measurements were taken.

Table 2

Microtomography scan intervals during in-situ FCG testing

\begin{tabular}{cccccccc}
\hline Tomography Scan & $\mathbf{1}^{\text {st }}$ & $\mathbf{2}^{\text {nd }}$ & $\mathbf{3}^{\text {rd }}$ & $\mathbf{4}^{\text {th }}$ & $\mathbf{5}^{\text {th }}$ & $\mathbf{6}^{\text {th }}$ & $\mathbf{7}^{\text {th }}$ \\
\hline Load min/max (N) & $87.8 / 878$ & $87.8 / 878$ & $87.8 / 878$ & $100 / 1000$ & $100 / 1000$ & $100 / 1000$ & $100 / 1000$ \\
Cycle Interval & 4200 & 3900 & 3900 & 1200 & 1200 & 1800 & 3900 \\
\hline
\end{tabular}

The individual radiographs were reconstructed into 3D volumes using GRIDREC algorithm [29,30]. These microtomography volumes had a voxel resolution of $1.48 \mu \mathrm{m}$. DREAM.3D software was used to segment the reconstructed volumes, using a simple threshold procedure, and then align the various datasets with each other [31]. The segmented and aligned reconstructions were then read into Paraview for visualization. A movie was created that shows the formation of the 3D crack with colors representing each time interval from Table 2, as well as the full reconstruction of the 3D crack with colors corresponding to elevation or $\mathrm{z}$ value of each pixel. This data was subsequently input into MATLAB and measurements were taken of crack lengths corresponding with each tomography scan. Knowledge of the number of cycles and the crack length corresponding with each scan yields the crack growth rates. This was done in directions $0^{\circ}, 45^{\circ}$, and $90^{\circ}$ from the notch corner in order to observe the variance in crack growth rate dependent on the direction of growth from the notch.

After the experiment, the fractured specimen underwent additional analysis. Optical microscopy was used to study the crack path through the microstructure. SEM was used to understand crack growth mechanisms, as well as to measure striation spacing to supplement the microtomography crack growth rate data. These rates were further compared with data obtained from previous long and small FCG tests.

\section{Results and discussion}

3.1. Tomography: 2D and 3D reconstructions 
The 2D cross-sections extracted along the tensile axis of the in-situ microtomography reconstructions are shown in Figures 5(a-e) from the $7^{\text {th }}$ (last) tomography scan. These 2D cross-section images show evidence of crack presence at multiple planes along the tensile axis, indicating that while the crack grew the fastest on the plane of the notch, Figure 5(c), there was also secondary crack branching above and below the main crack growth plane. Quantifying the crack characteristics in only 2D disregards this behavior, emphasizing the importance of observing the FCG in 3D.

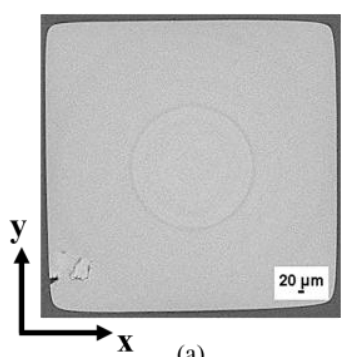

(a)

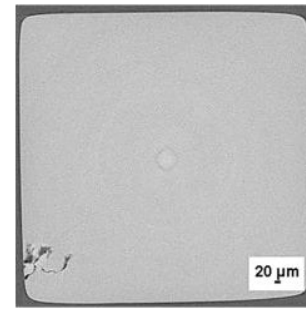

(b)

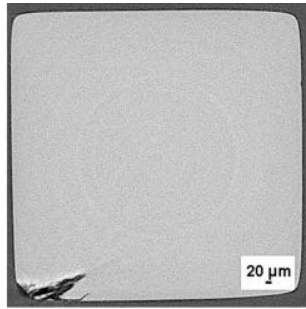

(c)

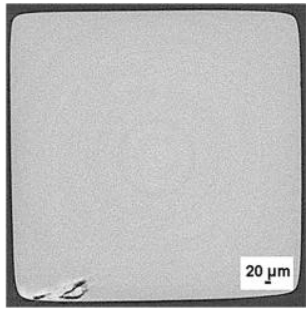

(d)

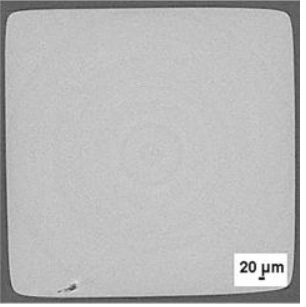

(e)

Fig. 5. Tomographic images showing gage cross sections of the fatigue specimen: $(a, b)$ beneath the notch level, (c) near the notch level (the notch is the dark triangle seen in the bottom left corner of the specimen), and (d,e) above the notch level.

Snapshots from the 3D microtomographic reconstruction are shown in Figures 6(a-g), representing the seven microtomographic scans during the fatigue experiment. The translucent grey box (dimension: $0.5 \mathrm{~mm} \times 0.5 \mathrm{~mm} \times 0.3 \mathrm{~mm}$ ) represents a quarter of the specimen volume. Each color represents a different tomography scan or time step, corresponding to different fatigue cycle intervals from Table 2 . A second 3D crack visualization was created with colors corresponding to different $\mathrm{z}$-coordinate values along the tensile axis of the specimen, as shown in Figure 6(h). Observation of the corresponding video reveals a local deflection during crack propagation, which resulted in varying local crack path roughness.

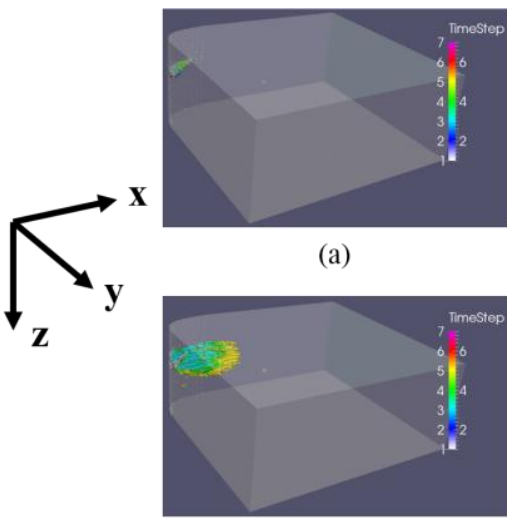

(e)

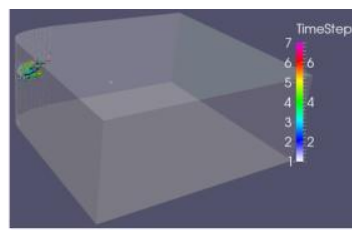

(b)

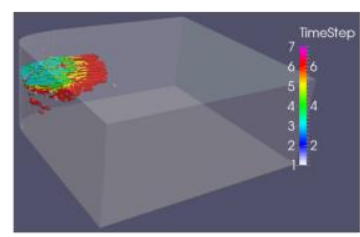

(f)

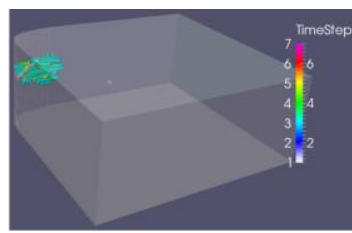

(c)

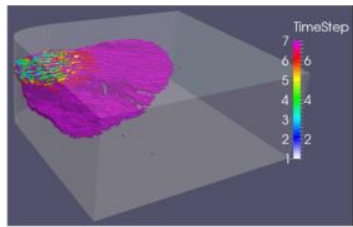

(g)

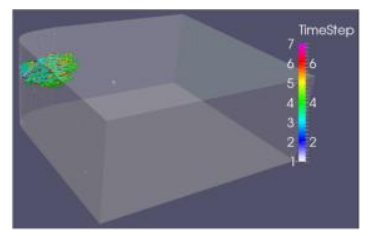

(d)

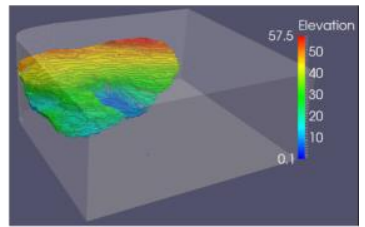

(h)

Fig. 6. Snapshots from 3D microtomography reconstructions: (a-g) crack propagation corresponding to the seven tomography scans listed in Table 2; (h) crack elevation at various locations on the propagation plane.

\subsection{Tomography: fatigue crack path - side profile and fracture surface analysis}

A panoramic view of the fatigue fracture surface (SEM) is shown in Figure 7(a). The white mark indicates the end of fatigue failure, separating fatigue fracture surface (area between the initial notch and the white line) from the tensile overload fracture surface (area outside the white line). The side profile of one half of the broken specimen (optical) is shown in Figure 7(b), indicating that crack propagation 
happened within one columnar $\beta$ grain. SEM analysis of the fatigue fracture surface was also conducted at various $\Delta \mathrm{K}$ values, and some key observations are shown in Figure 8. Cleavage steps/planes indicated a brittle behavior near the notch, Figures 8(a), similar to those observed near the long FCG threshold. Ductile fracture was observed at higher $\Delta \mathrm{K}$ towards the end of the test, Figure $8(\mathrm{c})$. Crack branching was also observed, as shown in Figure 8(b).

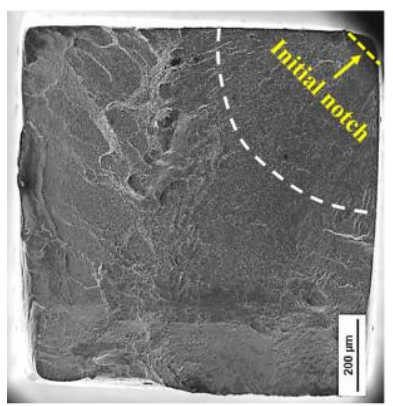

(a)

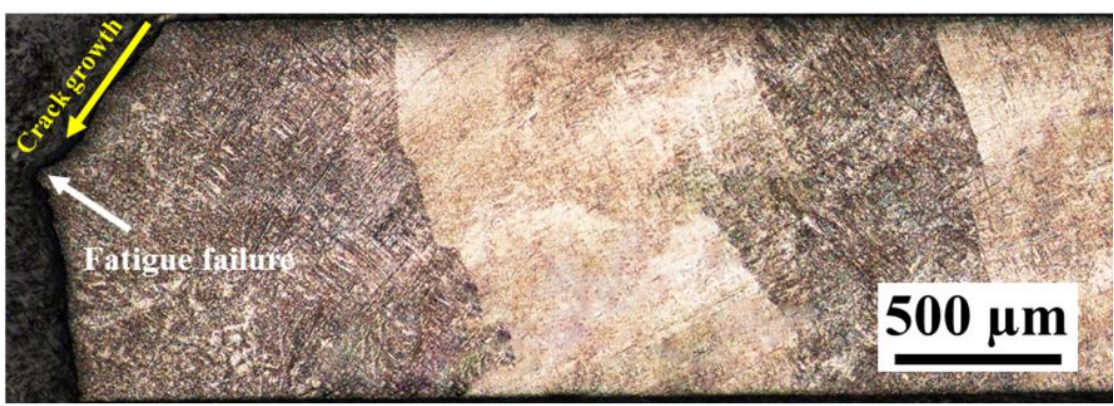

(b)

Fig. 7. Panoramic view of: (a) fatigue fracture surface; (b) side profile of the crack path.

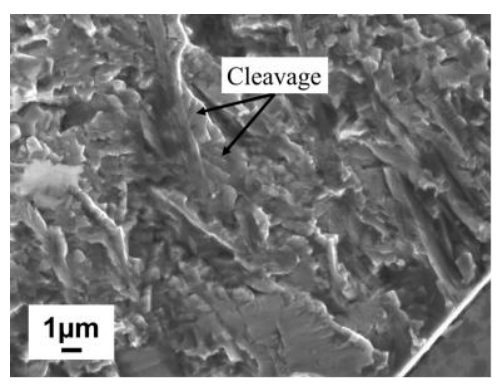

(a)

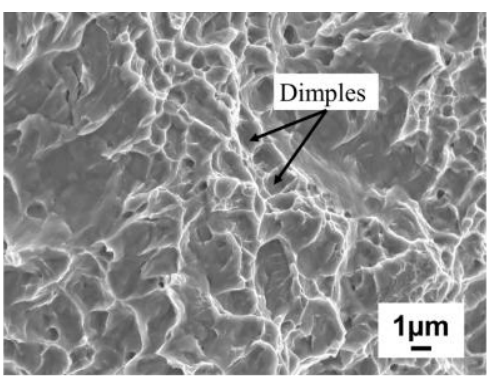

(b)

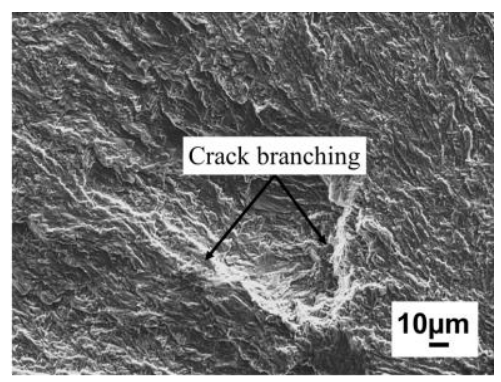

(c)

Fig. 8. SEM analysis: (a) elements of cleavage steps/planes indicating a brittle behavior during crack propagation; (b) end of the test indicating ductile fracture; (c) crack branching.

\subsection{Tomography: 2D and 3D data analysis and crack deflection corrections}

Crack lengths and growth rates were calculated for three FCG directions: $\theta=0^{\circ}, 45^{\circ}$, and $90^{\circ}$, as shown schematically in Figure 10(a). Crack lengths were calculated using simple geometric equations: (ii) for 2D calculation and (iii) for 3D calculation. In these equations, $\mathrm{x}, \mathrm{y}$, and $\mathrm{z}$ represents microtomographic coordinates, measured in MATLAB. Coordinates corresponding to four points were taken in each location where the corresponding direction arrows intersect with the crack edge. Crack lengths from the microtomography measurements ranged from approximately $20 \mu \mathrm{m}$ to $211 \mu \mathrm{m}$. Crack growth rates were determined using the calculated crack length and the cycle increment that corresponded to each microtomography scan. Stress intensity factors were then calculated using equation (i) with load and calculated crack length as inputs. The results of 2D and 3D calculations showing crack growth behavior in all three $\theta$ directions are plotted and compared in Figure 9.

$$
\begin{array}{r}
a_{2 D}=\sqrt{x^{2}+y^{2}} \\
a_{3 D}=\sqrt{x^{2}+y^{2}+z^{2}}
\end{array}
$$




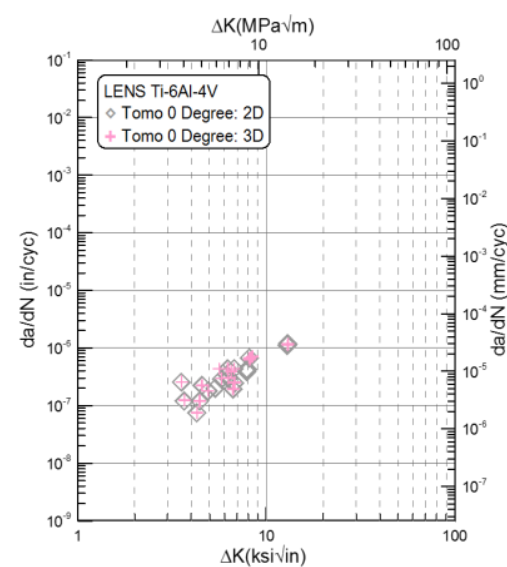

(a)

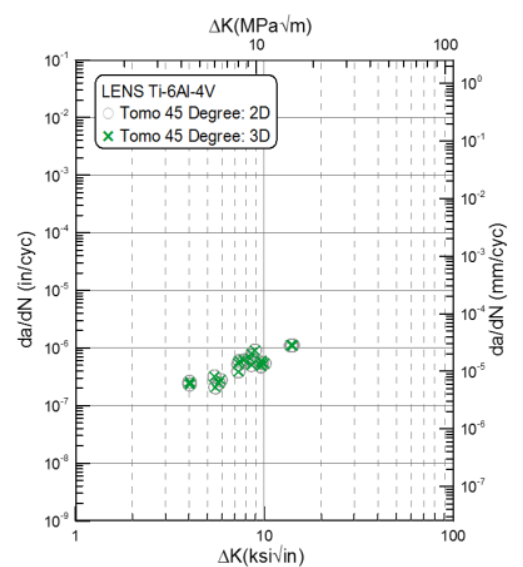

(b)

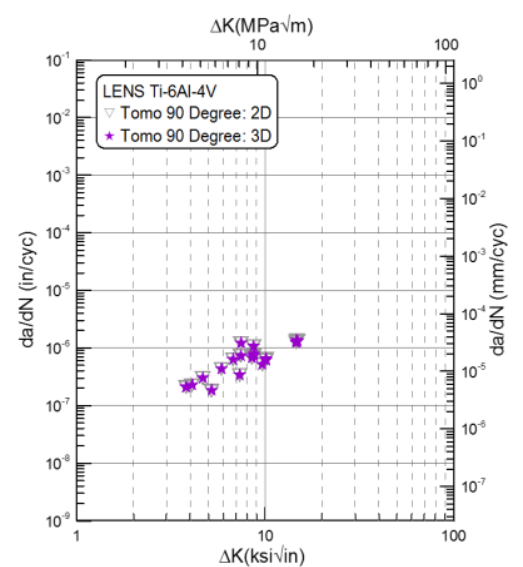

(c)

Fig. 9. Comparison between $2 \mathrm{D}$ and $3 \mathrm{D}$ microtomography FCG data for: (a) $\theta=0^{\circ}$; (b) $\theta=45^{\circ}$; and (c) $\theta$ $=90^{\circ}$.

The comparison of $2 \mathrm{D}$ and $3 \mathrm{D}$ values shows slight variation in crack growth rates. To quantify this variance, the percent error was calculated for each measured point. It was observed that for some data points, the error is minor (under 1\%). However, there were several points that showed error above $2 \%$ and some even more than $50 \%$. Such points reflect areas of crack growth where the crack grew significantly in the z-direction. In these cases, 2D crack length calculation neglects this important information and did not reflect accurately the crack growth rates. Thus, only the 3D data will be used in the following analysis. The 3D values for all three $\theta$ directions were also plotted together, along with the long and microstructurally small FCG data in Figure 10(b), which then reveals that variance in FCG behavior exist between the three directions. It was also observed that the microtomographic data have good agreement with the long FCG data in Region II, and trend towards the microstructurally small data at lower $\Delta \mathrm{K}$ values.

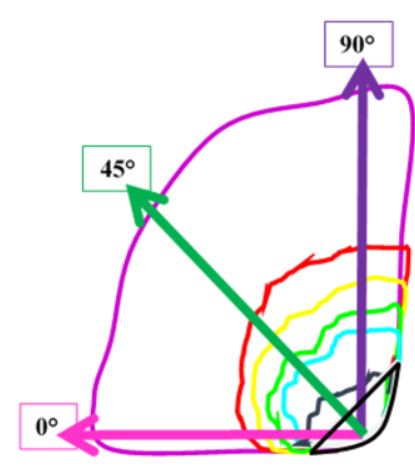

(a)

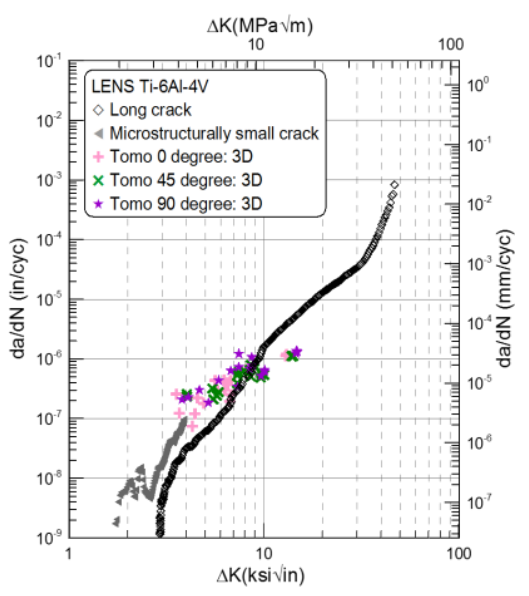

(b)

Fig. 10. 3D microtomographic FCG data: (a) schematic representation showing the three $\theta$ directions of microtomographic measurements; (b) comparison between 3D microtomographic data and long and small

FCG data.

The variance in growth rates between the three $\theta$ directions at the same crack front is characteristic of small crack behavior. The difference between the 2D and 3D calculations then demonstrate that local crack deflection could play an important role. These factors indicate that the angle of deflection $\alpha$ should 
be taken into account in the calculations of local $\Delta \mathrm{K}$ values. However, utilizing equation (i) to calculate $\Delta \mathrm{K}$ does not account for $\alpha$, and a different equation should be used to incorporate deflection angle into $\Delta \mathrm{K}$ evaluations. Ayhan et al. [32] developed a model that is able to describe stress intensity factors for deflected corner cracks under uniform tension. This relationship is shown in equation (iv) for mode-I behavior (subscript $\mathrm{i}=1$ ), which is normalized by equations (v) and (vi). The constants in equation (iv) are listed in Table 3. The schematic representation of the crack geometry and related parameters are shown in Figure 11. It should be noted that this model is not recommended to be used for cases in which $\alpha \geq 60^{\circ}$.

$$
\begin{gathered}
\mathrm{K}_{1}^{\mathrm{N}}=\left(\mathrm{a}_{1}+\mathrm{b}_{1}\left(\frac{\mathrm{a}}{\mathrm{t}}\right)^{2}\right) \sin ^{2}\left(\mathrm{c}_{1}+\mathrm{d}_{1} \alpha\right) \cosh \left(\mathrm{e}_{1}+\mathrm{f}_{1} \theta\right) \\
\mathrm{K}_{1}^{\mathrm{N}}=\frac{\mathrm{K}_{1}}{\mathrm{~K}_{\mathrm{R}}} \\
\mathrm{K}_{\mathrm{R}}=\sigma_{0} \sqrt{\frac{\pi * \mathrm{a}}{\mathrm{Q}}}
\end{gathered}
$$

where,

$\sigma_{0}$ is the remote uniform tension stress (MPa)

$\mathrm{a}$ is the crack length $(\mathrm{m})$

$\mathrm{Q}$ is the shape factor, and for corner crack: $\mathrm{Q}=2.464$

$\mathrm{K}_{1}^{\mathrm{N}}$ is the normalized mode-I stress intensity factor $(\mathrm{MPa} \vee \mathrm{m})$

$\mathrm{t}$ is the thickness of the plate $(\mathrm{m})$

$\alpha$ is the crack plane deflection angle (radians)

$\theta$ is the crack front position angle (radians)

$\mathrm{a}_{1}-\mathrm{f}_{1}$ are constants (Table 3 )

\section{Table 3}

Constants in equation (vi) for evaluation of stress intensity factor for deflected corner cracks under uniform tension [32]

\begin{tabular}{ccccccc}
\hline Constants & $\mathrm{a}_{1}$ & $\mathrm{~b}_{1}$ & $\mathrm{c}_{1}$ & $\mathrm{~d}_{1}$ & $\mathrm{e}_{1}$ & $\mathrm{f}_{1}$ \\
\hline & 1.12440 & 0.44752 & 1.58160 & 0.88839 & -0.42826 & 0.52634 \\
\hline
\end{tabular}

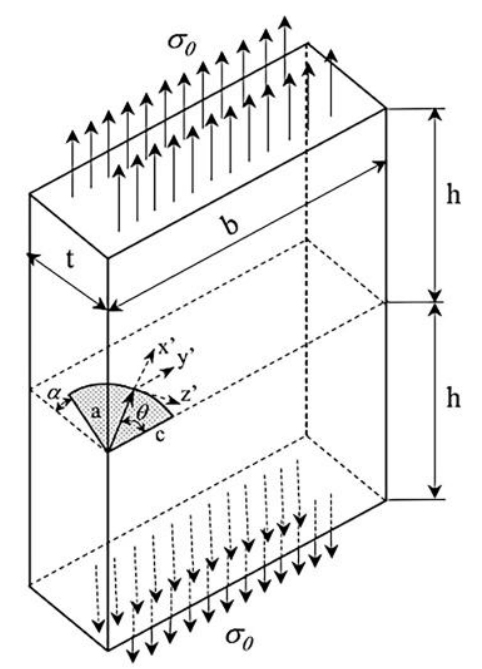

Fig. 11. Schematic related to equations (iv-vi) showing a corner crack with deflection angle $\alpha$ [32]. 
In order to apply these equations, the deflection angles $\alpha$ were calculated for every microtomography measurement, and the results are listed in Table 4. A comparison between deflection angles $\alpha$ for different $\theta$ directions from the corner notch indicates that the most deflection was experienced in the $\theta=$ $0^{\circ}$ direction. This is likely related to the fact that in-plane crack growth in that direction was less than that in the $\theta=45^{\circ}$ and $\theta=90^{\circ}$ directions.

\section{Table 4}

Average deflection angle $(\alpha)$ at various crack growth directions $(\theta)$ from the corner notch

\begin{tabular}{cccc}
\hline \multirow{2}{*}{ Crack Growth Interval: Corresponding Tomography Scans } & \multicolumn{3}{c}{ Average Deflection Angle, $\alpha$} \\
\cline { 2 - 4 } & $\theta=0^{\circ}$ & $\theta=45^{\circ}$ & $\theta=90^{\circ}$ \\
\hline $1-2$ & 9.74 & 2.03 & 0.34 \\
$3-3$ & 3.69 & 0.81 & 3.70 \\
$4-5$ & 9.37 & 1.62 & 3.78 \\
$5-6$ & 9.51 & 3.76 & 2.51 \\
$6-7$ & 21.44 & 4.02 & 1.17 \\
\hline
\end{tabular}

Using the deflection angles $\alpha, \Delta \mathrm{K}$ values were recalculated for all three crack growth directions and are plotted in Figure 12. The results indicate a slight shift in $\Delta \mathrm{K}$ after the incorporation of the deflection angle $\alpha$. Because these new values incorporate the deflection, they are the most accurate representation of the crack growth data obtained from tomography, and will be used in the next section for comparisons with the crack growth data obtained from fracture surface striation measurements.

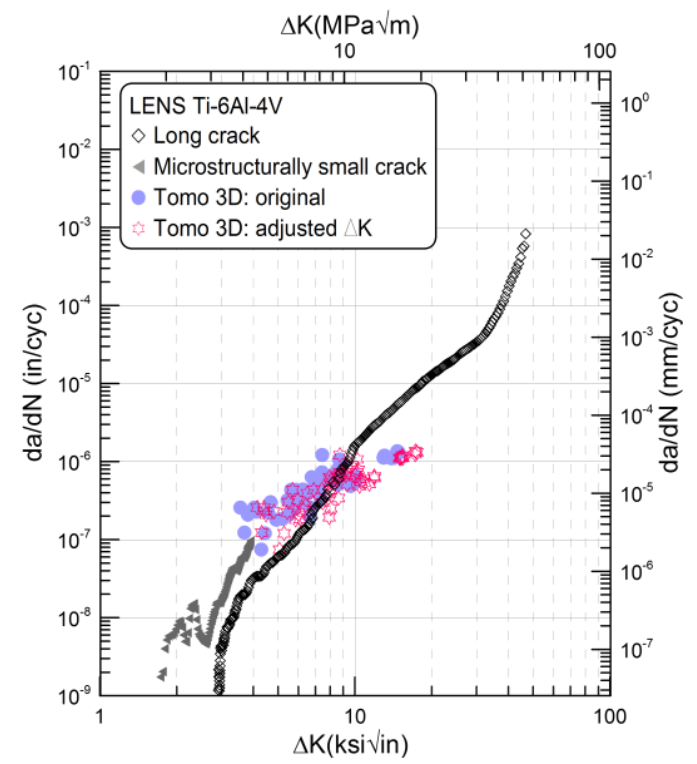

Fig. 12. Microtomography FCG data points with and without incorporation of deflection angle $\alpha$.

\subsection{Striation spacing measurements}

Striation spacing (S) values were also measured to evaluate crack growth rates. Average $S$ values were calculated and represented by the quotient of the length of a line and the number of intercepting striations. Striation spacing represents the crack propagation per cycle, thus the local $\mathrm{da} / \mathrm{dN}$ can be represented by $\mathrm{S} /$ cycle. Striations were measured beyond the locations captured by microtomography, where $\theta=0^{\circ}, 45^{\circ}$, and $90^{\circ}$ arrows intersected with the microtomography crack profile at each time step. 
FCG rates calculated from microtomography data were plotted together with FCG rates from striation measurements as shown in Figure 13. SEM images of striations corresponding with first and last points for $\theta=0^{\circ}, 45^{\circ}$, and $90^{\circ}$ are shown in Figure 14. While striation measuring results show good agreement with the long FCG data in upper Region II, variations were observed from comparisons of striation measurements with microtomography (3D, deflection corrected) data at similar crack lengths.

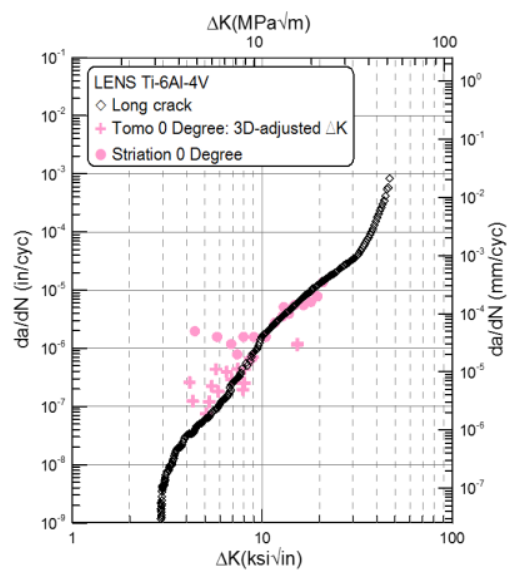

(a)

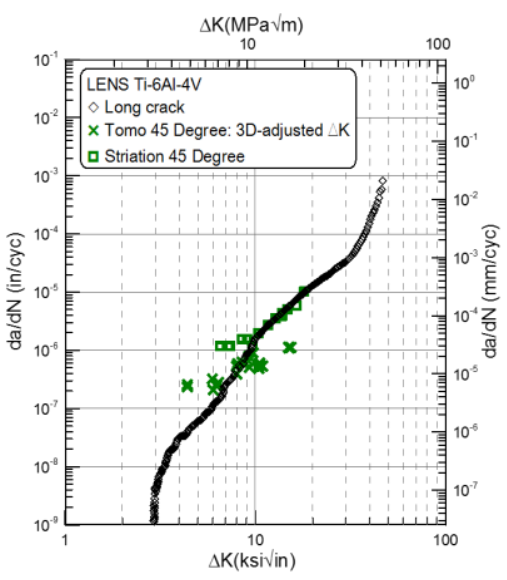

(b)

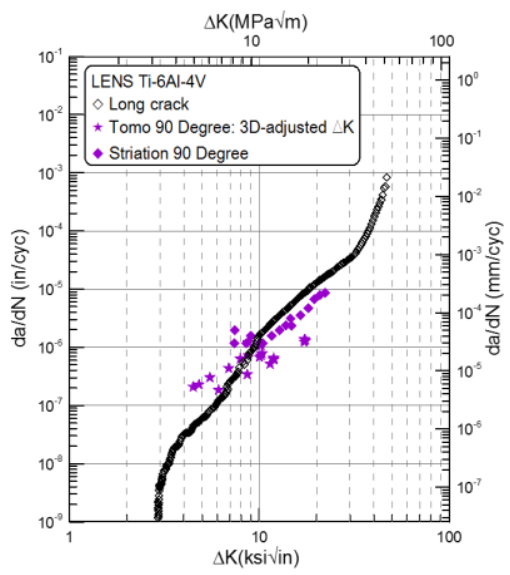

(c)

Fig. 13. Comparison between FCG data obtained from striation spacing and tomography measurements for: (a) $\theta=0^{\circ}$; (b) $\theta=45^{\circ}$; and (c) $\theta=90^{\circ}$ directions.

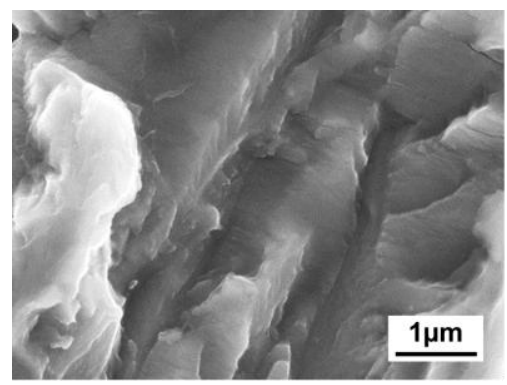

(a) $\triangle \mathrm{K} \sim 4.4 \mathrm{MPa} \sqrt{\mathrm{m}}$ $\mathrm{S}=0.02 \mu \mathrm{m}$

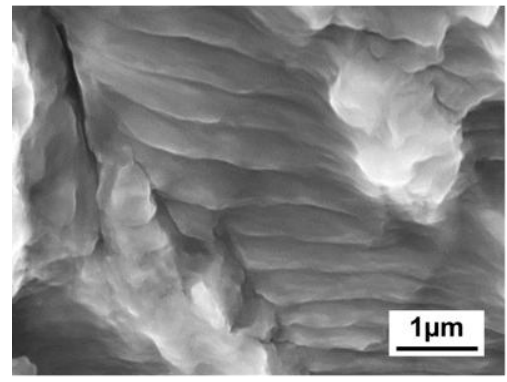

(d) $\Delta \mathrm{K} \sim 21 \mathrm{MPa} \sqrt{\mathrm{m}}$ $\mathrm{S}=0.35 \mu \mathrm{m}$

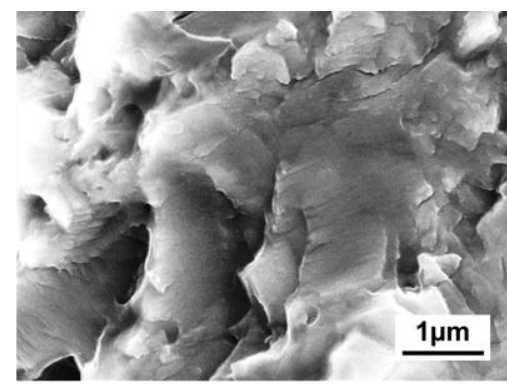

(b) $\Delta \mathrm{K} \sim 6.5 \mathrm{MPa} \sqrt{\mathrm{m}}$ $\mathrm{S}=0.02 \mu \mathrm{m}$

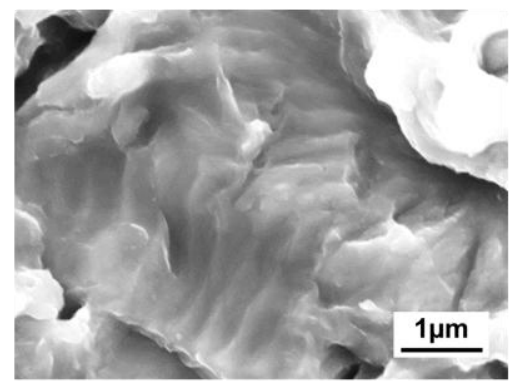

(e) $\Delta \mathrm{K} \sim 18 \mathrm{MPa} \sqrt{\mathrm{m}}$ $\mathrm{S}=0.26 \mu \mathrm{m}$

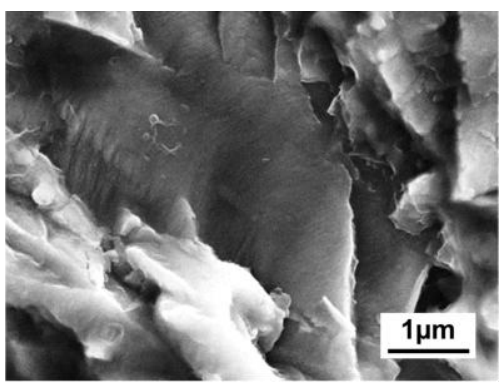

(c) $\Delta \mathrm{K} \sim 7.4 \mathrm{MPa} \sqrt{\mathrm{m}}$ $\mathrm{S}=0.03 \mu \mathrm{m}$

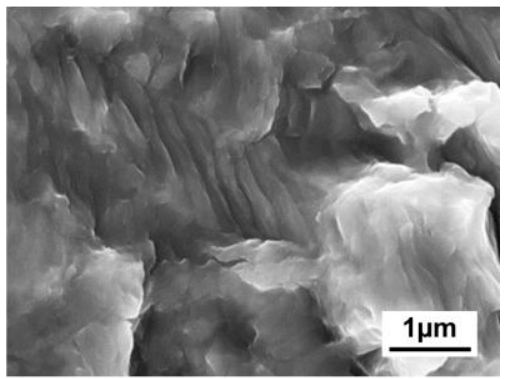

(f) $\Delta \mathrm{K} \sim 22 \mathrm{MPa} \sqrt{\mathrm{m}}$ $\mathrm{S}=0.22 \mu \mathrm{m}$

Fig. 14. SEM images from the first and last striation measurement locations in: (a,d) $\theta=0^{\circ}$; (b,e) $\theta=45^{\circ}$; $(\mathrm{c}, \mathrm{f}) \theta=90^{\circ}$ directions.

It was observed that FCG data generated from striation spacing measurements show good agreement with microtomography data at $\Delta \mathrm{K}=8-10 \mathrm{MPa} \sqrt{\mathrm{m}}$. However, increasingly less agreement was observed below $\Delta \mathrm{K}=8 \mathrm{MPa} \sqrt{\mathrm{m}}$. Several phenomena contribute to this behavior: (1) striations seldom occur during 
early stages of FCG; (2) the very small $20 \mu \mathrm{m}$ crack was subjected to a large $1000 \mathrm{~N}$ load, which may have introduced some plasticity, causing deformation and blunting of the crack until the crack stabilized around $\Delta \mathrm{K}=8 \mathrm{MPa} \sqrt{\mathrm{m}}$; (3) when the stress intensity is below a certain level, a number of cycles are required for the crack to grow one striation, making striation spacing an inaccurate representation of crack growth per cycle; (4) the local micro-scale angular crack deflection could not be accurately accounted for when the striations were measured. This behavior is what would be expected for microstructurally small cracks. This work demonstrates the differences between microstructurally small and long crack growth behavior and provides means to evaluate them combining microtomography with SEM studies and analytical models. In addition, microtomography measurements are able to visualize the crack in 3D, enabling a more accurate capturing of the crack growth behavior.

\subsection{Compilation of long, small, and tomography-evaluated FCG data}

FCG data (tomography and striation measurements) from the in-situ 3D microtomography experiment are compared to the long and microstructurally small crack FCG data from previous studies, as shown in Figure 15. The 3D tomography data shows good agreement with the long crack data $(\mathrm{R}=0.1)$ in lower Paris Region II of crack growth, and a consistent connection to the microstructurally small crack growth data $(\mathrm{R}=0.1)$ towards lower $\Delta \mathrm{K}$ values. Data from the striation measurements meanwhile, yields good agreement with the long FCG data in upper Region II. The tomography data also shows more scattering compared to the long data, reflecting the location dependent growth behavior of small cracks, and the influence of local microstructural features during small FCG. These findings illustrate good potential of using such non-destructive 3D techniques to observe both microstructurally small and long FCG behavior, and confirms the importance of this study towards building a systematic understanding of the FCG response of Ti-6Al-4V made by LENS.

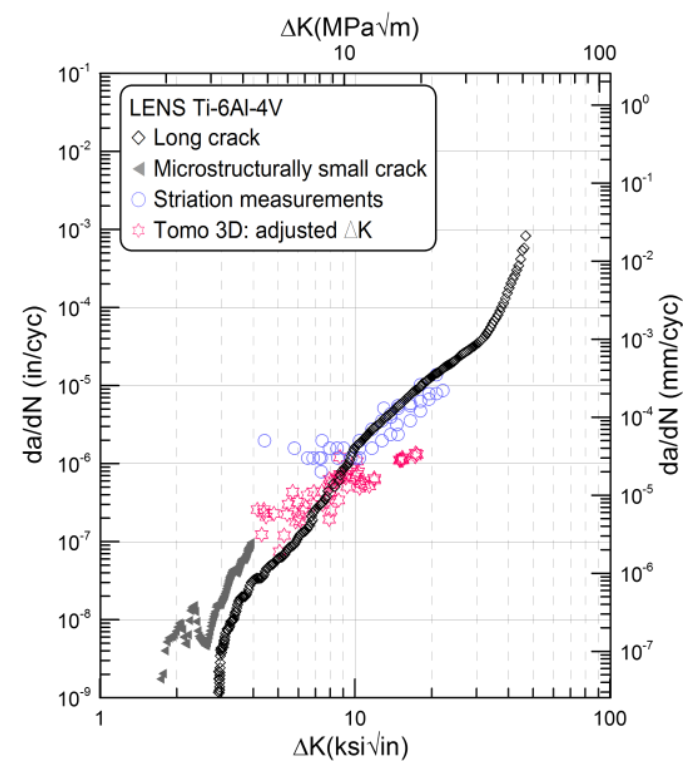

Fig. 15. Compiled FCG data for LENS fabricated Ti-6Al-4V.

\section{Conclusions}

In this study, FCG behavior of LENS fabricated Ti-6Al-4V was observed using synchrotron x-ray microtomography. This method allowed 3D in-situ observation of crack propagation. Crack growth through a typical LENS Ti-6Al-4V martensitic microstructure was successfully captured. It was observed that crack growth occurred primarily in-plane, with some out-of-plane deflections along the tensile axis, indicating local crack growth variation and emphasizing the importance of local 3D observation and 
characterization of FCG. The advance of the crack front was not equal in all growth directions. Local variance in crack growth rate data was also noted, which indicates location-dependent crack deflection. A comparison between crack growth rates obtained from microtomography reconstructions and striation spacing measurements indicated the importance of using 3D methods to observe the earlier stages of crack growth, where striation measurements are not an accurate representation of the crack growth rates. Use of microtomography and the proposed evaluation method can help enable a more physically-realistic understanding and characterization of the FCG behavior in LENS fabricated Ti-6Al-4V. Future work should include fatigue crack propagation in different orientations, to understand the effects of directionality and investigate the crack interaction with columnar grain boundaries, as illustrated by specimens 2 and 3 in Figure 4(a).

\section{Acknowledgements}

The authors thank the consortium members of the Integrative Materials Design Center (iMdc) for their support of the AM research at WPI, especially Eric Brown and Gregory Vigilante from Benét Laboratories for providing the LENS Ti-6Al-4V materials, Todd Turner (Air Force Research Laboratory, (AFRL)), Basil Blank (PulseRay), and the 1-ID beamline staff at Advanced Photon Source (APS): JunSang Park, Ali Mashayekhi, and Jonathan Almer for useful discussions and experimental assistance. The experiments were completed under GUP 36599 at the APS. Use of the APS, an Office of Science User Facility operated for the U.S. Department of Energy (DOE) Office of Science by Argonne National Laboratory (ANL), was supported by the U.S. DOE under Contract No. DEAC02-06CH11357.

\section{References}

[1] ISO-ASTM, ISO/ASTM 52900: Standard Terminology for Additive Manufacturing - General Principles - Terminology, 2015.

[2] M.L. Griffith, M.T. Ensz, J.D. Puskar, C.V. Robino, J.A. Brooks, J.A. Philliber, J.E. Smugeresky and W.H. Hofmeister, Understanding the Microstructure and Properties of Components Fabricated by Laser Engineered Net Shaping (LENS), Mater. Res. Soc. Symp. Y. Proc., 2000, vol. 625, pp. 9-20.

[3] F. Wang, J. Mei and X. Wu, Microstructure study of direct laser fabricated Ti alloys using powder and wire, Appl. Surf. Sci., 2006, vol. 253, pp. 1424-1430.

[4] X. Wu and J. Mei, Near net shape manufacturing of components using direct laser fabrication technology, J. Mater. Process. Technol., 2003, vol. 135, pp. 266-270.

[5] X. Wu, J. Liang, J. Mei, C. Mitchell, P.S. Goodwin and W. Voice, Microstructures of laser-deposited Ti-6Al-4V, Mater. Des., 2004, vol. 25, pp. 137-144.

[6] L. Qian, J. Mei, J. Liang and X. Wu, Influence of position and laser power on thermal history and microstructure of direct laser fabricated Ti-6Al-4V samples, Mater. Sci. Technol., 2005, vol. 21, pp. 597-605.

[7] A.J. Sterling, B. Torries, N. Shamsaei, S.M. Thompson, and D.W. Seely, Fatigue behavior and failure mechanisms of direct laser deposited Ti-6Al-4V, Mat. Sci. \&Eng. A, 2016, vol. 655, pp. 100-112

[8] E. Amsterdam and G.A. Kool, High Cycle Fatigue of Laser Beam Deposited Ti-6Al-4V and Inconel 718, ICAF, Bridg. Gap between Theory Oper. Pract., Springer, The Netherlands, 2009, pp. 1261-1274.

[9] L. Bian, S.M. Thompson, and N. Shamsaei, Mechanical Properties and Microstructural Features of Direct Laser-Deposited Ti-6Al-4V, JOM, 2015, vol. 67, pp. 629-638.

[10] Y. Zhai, D.A. Lados, E.J. Brown, and G.N. Vigilante, Fatigue crack growth behavior and microstructural mechanisms in Ti-6Al-4V manufactured by laser engineered net shaping, Int. J. Fatigue, 2016, vol. 93, pp. 51-63.

[11] J. Rethore, L. Nathalie, J.Y. Buffiere, S. Roux, and F. Hild, Three-dimensional analysis of fatigue crack propagation using X-Ray tomography, digital volume correlation and extended finite element simulations, Procedia IUTAM, 2012, vol. 4, pp. 151-158. 
[12] S.S. Singh, J.J. Williams, X. Xiao, F. De Carlo, and N. Chawla, In situ three dimensional (3D) X-ray synchrotron tomography of corrosion fatigue in A17075 alloy, Fatigue of Materials II: Advances and Emergences in Understanding, John Wiley \& Sons, Inc., Hoboken, NJ, 2013, pp. 17-25.

[13] J.J. Williams, K.E. Yazzie, E. Padilla, N. Chawla, X. Xiao and F. De Carlo, Understanding fatigue crack growth in aluminum alloys by in situ X-ray synchrotron tomography, Int. J. Fatigue, 2013, vol. 57, pp. 79-85.

[14] J.J. Williams, K.E. Yazzie, N.C. Phillips, N. Chawla, X. Xiao, F. De Carlo, N. Iyyer and M. Kittur, On the Correlation Between Fatigue Striation Spacing and Crack Growth Rate: A Three-Dimensional (3D) X-ray Synchrotron Tomography Study, Metall. Trans. A, 2011, vol. 42A, pp. 3845-3848.

[15] W. Ludwig, J.Y. Buffere, S. Savelli and P. Cloetens, Study of the interaction of a short fatigue crack with grain boundaries in a cast Al alloy using x-ray microtomography, Acta Mater., 2003, vol. 51, pp. 585-598.

[16] E. Ferrie, J.Y. Buffiere and W. Ludwig, 3D characterisation of the nucleation of a short fatigue crack at a pore in a cast $\mathrm{Al}$ alloy using high resolution synchrotron microtomography, Int. J. Fatigue, 2005, vol. 27, pp. 1215-1220.

[17] S. Birosca, J.Y. Buffiere, F.A. Garcia-Pastor, M. Karadge, L. Babout and M. Preuss, Threedimensional characterization of fatigue cracks in Ti-6246 using $\mathrm{x}$-ray tomography and electron backscatter diffraction, Acta Mater., 2009, vol. 57, pp. 5834-5847.

[18] S. Birosca, J.Y. Buffiere, M. Karadge and M. Preuss, 3-D observations of short fatigue crack interaction with lamellar and duplex microstructures in a two-phase titanium alloy, Acta Mater., 2011, vol. 59, pp. 1510-1522.

[19] M. Herbig, A. King, P. Reischig, H. Proudhon, E.M. Lauridsen, J. Marrow, J.Y. Buffiere and W. Ludwig, 3-D growth of a short fatigue crack within a polycrystalline microstructure studied using combined diffraction and phase-contrast x-ray tomography, Acta Mater., 2011, vol. 59, pp. 590-601.

[20] A. King, W. Ludwig, M. Herbig, J.Y. Buffiere, A.A. Khan, N. Stevens, and T.J. Marrow, Threedimensional in situ observations of short fatigue crack growth in magnesium, Acta Mater., 2011, vol. 59, pp. 6761-6771.

[21] P.J. Withers and M. Preuss, Fatigue and damage in structural materials studied by $x$-ray tomography, Ann. Rev. Mater. Res., 2012, vol. 42, pp. 81-103.

[22] H. Proudhon, A. Moffat, I. Sinclair and J.Y. Buffiere, Three-dimensional characterisation and modelling of small fatigue corner cracks in high strength Al-alloys, C. R. Phys., 2012, vol. 13, pp. 316327.

[23] A.D. Spear, S.F. Li, J.F. Lind, R.M. Suter and A.R. Ingraffea, Three-dimensional characterization of microstructurally small fatigue-crack evolution using quantitative fractography combined with postmortem x-ray tomography and high-energy x-ray diffraction microscopy, Acta Mater., 2014, vol. 76, pp. 413-424.

[24] A. Khounsary, P. Kenesei, J. Collins, G. Navrotski, and J. Nudell, High Energy X-ray Microtomography for the characterization of thermally fatigued GlidCop specimen, J. Phys.: Conf. Ser., 2013, vol. $425,212015$.

[25] ASTM-International, ASTM Standard E647: Standard Test Method for Measurement of Fatigue Crack Growth Rates, 2015.

[26] J.C. Schuren, P.A. Shade, J.V. Bernier, S.F. Li, B. Blank, J. Lind, P. Kenesei, U. Lienert, R.M. Suter, T.J. Turner, D.M. Dimiduk and J. Almer, New opportunities for quantitative tracking of polycrystal responses in three dimensions, Curr. Opin. Solid State Mater. Sci., 2015, vol. 19, pp. 235-244.

[27] P.A. Shade, B. Blank, J.C. Schuren, T.J. Turner, P. Kenesei, K. Goetze, R.M. Suter, J.V. Bernier, S.F. Li, J. Lind, U. Lienert and J. Almer, A rotational and axial motion system load frame insert for in situ high energy x-ray studies, Rev. Sci. Instrum., 2015, vol. 86, pp. 093902.

[28] H. Tada, P.C. Paris, and G.R. Irwin, The stress analysis of cracks handbook, The American Society of Mechanical Engineers, New York, 2000. 
[29] B.A. Dowd, G.H. Campbell, R.B. Marr, V.V. Nagarkar, S.V. Tipnis, L. Axe and D.P. Siddons, Developments in synchrotron x-ray computed microtomography at the National Synchrotron Light Source, Proc. SPIE: Developments in X-Ray Tomography II, 1999, vol. 3772, pp. 224-236.

[30] Y. Wang, F. De Carlo, I. Foster, J. Insley, C. Kesselman, P. Lane, G. von Laszewski, D.C. Mancini, M. Su and B. Tieman, Quasi-real-time x-ray microtomography system at the Advanced Photon Source, Proc. SPIE: Developments in X-Ray Tomography II, 1999, vol. 3772, pp. 318-327.

[31] M.A. Groeber and M.A. Jackson, DREAM.3D: a digital representation environment for the analysis of microstructure in 3D, Integr. Mater. Manuf. Innov., 2014, vol. 3, pp. 5.

[32] A.O. Ayhan and U. Yücel, Stress intensity factor equations for mixed-mode surface and corner cracks in finite-thickness plates subjected to tension loads, Int. J. Pressure Vessels Piping, 2011, vol. 88, pp. 181-188. 